\title{
EFEKTIFITAS MEDIA SOSIAL SEBAGAI ALAT PROMOSI PADA SEKOLAH MENENGAH KEJURUAN DI BEKASI
}

\author{
Andreas Adi Trinoto \\ Program Studi Informatika, Universitas Indraprasta PGRI \\ a.trinoto@gmail.com
}

\begin{abstract}
Abstrak
Saat promosi konvensional penerimaan siswa baru menjadi satu-satunya alat pemasaran pada Sekolah Menengah Kejuruan, maka dibutuhkan alat dan strategi [14] baru yang mumpuni untuk menghadapi tantangan teknologi. Dengan adanya media sosial seperti Facebook, Twitter dan Instagram, penggunaannya telah menjadi suatu ide untuk menjawab kebutuhan sekolah [12]. Data primer yang dikumpulkan berupa kuantitatif dan kualitatif, berdasarkan atas survei kuesioner dan wawancara tentang media yang selama ini digunakan. Regresi Linier digunakan untuk mencari pengaruh antar variabel dan Diagram Ishikawa / Fishbone, merupakan alat untuk mencari dan mengidentifikasi sebab dari masalah. Penelitian ini menemukan fakta bahwa investasi pada teknologi, khususnya media sosial ternyata belum mendapat hasil yang maksimal pada penerimaan siswa SMK Yadika 6 tahun ajaran 2016/2017.
\end{abstract}

Kata Kunci : Diagram Ishikawa (Fishbone), Media Sosial (Facebook, Twitter dan Instagram), Alat Promosi SMK.

\begin{abstract}
When conventional promotion of new student admissions become the only means of marketing at Vocational High School, the new tool and strategy [14] is needed that qualified to face the challenges of technology. With the social media such as Facebook, Twitter and Instagram, its use has become an idea to answer the needs of the school[12]. Primary data collected in the form of quantitative and qualitative, based on a questionnaire survey and interviews on media that has been used. Linear regression was used to seek influence between variables and Diagram Ishikawa / Fishbone, a tool to locate and identify the cause of the problem. This study found that investments in technology, particularly social media has yet not to get the maximum results in the acceptance of vocational students Yadika 6 academic year 2016/2017.
\end{abstract}

Key Words : Ishikawa/Fishbone Diagram, Media Social (Facebook, Twitter and Instagram), Vocational High School promotion tool.

\section{PENDAHULUAN}

Pena lebih tajam daripada pedang, ungkapan Bulwer-Lytton [1] yang dipakai saat media cetak berjaya ternyata saat ini masih berlaku melalui teknologi informasi khususnya media sosial hanya saja tidak dengan pena. Seseorang dapat dengan mudah mengunggah gambar, video ataupun hanya membuat tulisan suatu kejadian tertentu dan menyebarkannya di situs jaringan sosial, sehingga terjadi gelombang yang berdampak pada kehidupan sosial [2].

Dampak positif dirasakan sekolah yang menggunakan Facebook sebagai pembelajaran kolaboratifnya [3],[10].
Kemudian penelitian [4] dengan jasa Twitter untuk alat pendukung kegiatan sekolahnya. Beberapa sekolah atau kampus telah membuat "virtual kampus" untuk kepentingan pembelajarannya [5].

Penggunaan dan pemahaman media sosial sebagai alat promosi pada dunia pendidikan [20], [6] menjadi penting dan dapat digunakan bagi sekolah dengan dukungan ICT yang memadai, serta sumber daya manusia yang mumpuni dalam bidang ini.

Penelitian ini bertujuan untuk menjawab seberapa besar dampak media sosial sebagai promosi, penggunaan ICT 
mengikuti perkembangan teknologi [13] pada pola penerimaan siswa baru SMK Yadika 6 Bekasi. Manfaat yang dapat diambil dari penelitian ini adalah memberikan alternatif pandangan tentang media promosi untuk mengambil keputusan dengan lebih mudah, relevan dengan perkembangan teknologi, sesuai dengan kebutuhan siswa dan tepat sasaran.

\section{METODE PENELITIAN}

Subjek dari penelitian ini adalah siswa baru SMK Yadika 6 yang memiliki dan menggunakan media sosial seperti Facebook, Twitter, dan Instagram, dan tentunya mengetahui akun media sosial SMK Yadika 6. Akun Facebook SMK Yadika 6 yaitu www.facebook.com/psbsixer dengan 400 friends, yadikasixer digunakan sebagai akun Twitternya dengan 17 followers, dan pada Instagram digunakan akun smk_yadika_6 dengan 247 followers. Objek penelitian ini adalah promosi penerimaan siswa baru SMK Yadika 6, khususnya pada akun Facebook, Twitter dan Instagram.

Metodologi riset kuantitatif digunakan dengan model survei deskriptif, survei ini menggambarkan populasi yang sedang diteliti. Data dipelajari dari sampel dari populasi tersebut, sehingga ditemukan fenomena relatif dan hubungan antar variabel. Setelah mendapat hasil maka dilakukan riset kualitatif, "Analisa kualitatif tidak menolak semua bentuk analisa kuantitatif" [7]. Metode tulang ikan Ishikawa (8P, namun diambil 6P) dijalankan untuk mencari sebab akibat keberhasilan penerimaan siswa baru pada SMK Yadika 6.

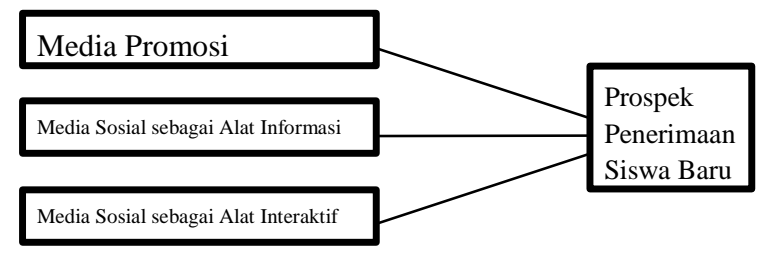

Gambar 1. Kerangka Pemikiran Penelitian

Sugiyono [8] menjelaskan populasi sebagai keseluruhan objek atau fenomena yang diteliti. Populasi dalam penelitian ini adalah siswa baru yang diterima pada SMK Yadika 6, yang berjumlah 252 orang. Menggunakan rumus Slovin, dimana $n$ adalah ukuran sampel, $\mathrm{N}$ adalah ukuran populasi dan e adalah galat pendugaan $(10 \%)$.

$$
\begin{aligned}
\mathrm{n} & =\mathrm{N} /\left[1+\mathrm{N}(\mathrm{e})^{2}\right] \\
& =252 / 1+\left(252 * 0.1^{2}\right) \\
& =72 \text { sampel. }
\end{aligned}
$$

Mengacu ke metode Slovin, peneliti mengambil data sebesar 75 dari total populasi karena total kuisioner yang kembali dan telah diisi secara lengkap dan sempurna berjumlah 75 kuisioner.

Metode pengambilan sampel yang digunakan dalam penelitian ini adalah Non-Probability Sampling dengan prosedur Convenience Sampling. NonProbability Sampling adalah metode pengambilan sampel berdasarkan penilaian peneliti sehingga tiap anggota populasi tidak memiliki kesempatan yang sama untuk menjadi sampel [9] . Convenience Sampling adalah suatu tipe prosedur dimana peneliti dalam memilih sampel individu yang mau dan bersedia mengisi kuesioner.

Pengolahan seluruh data di masukkan dan di proses dengan Microsoft Excel Versi 15.13.3 C2015. Analisis Mean Score (Skor Rataan) digunakan untuk membandingkan 
antara indikator tiap variabel di dalam model penelitian, pengujian Regresi Linier digunakan untuk menganalisis ketergantungan antara variabel independen dan variabel dependen.

Dalam pengujian hipotesis regresi, pengujian secara simultan adalah pengujian koefisien regresi secara parsial $(\mathrm{t}$ stat) untuk mengukur kemampuan model dalam variasi variabel dependen, nilai yang mendekati satu berarti variabel independen makin luas menjelaskan variabel dependen. Hipotesis yang dapat diuji adalah :

HO : variabel independen bukan penjelas yang signifikan terhadap variabel dependen.

H1 : variabel independen merupakan penjelas yang signifikan terhadap variabel dependen.

Dengan ketentuan berdasarkan probabilitas :

H0 diterima jika signifikan > 0.05

H0 ditolak jika signifikan $<0.05$

Berdasarkan nilai t hitung :

H0 diterima jika $\mathrm{t}$ hitung $<\mathrm{t}$ tabel

$\mathrm{H} 0$ ditolak jika $\mathrm{t}$ hitung $>\mathrm{t}$ tabel

Diagram Ishikawa (tulang ikan) yang dijabarkan menjadi 6 P yaitu

1. Product (Produk / Jasa) dengan pertanyaan : apakah jasa promosi kurang tepat? dan apakah jasa promosi tidak diterima calon siswa?;

2. Price (Harga) dengan pertanyaan : apakah biaya promosi tidak sesuai?, apakah anggaran pendukung tidak disiapkan?;

3. Place (Tempat) dengan pertanyaan : apakah penempatan iklan tidak sesuai?, apakah pembagian brosur salah sasaran?, dan apakah pemilihan media sosial tidak tepat?;

4. Promotion (Promosi) dengan pertanyaan : apakah sekolah melakukan kerjasama dengan pihak provider?, dan apakah tidak ada sosialisasi promosi?;

5. People (Manusia) dengan pertanyaan : apakah karyawan mampu melakukan tugas?, apakah karyawan tidak tahu prosedur pemasangan iklan?, apakah karyawan tidak mengikuti prosedur pemasangan iklan?, apakah karyawan tidak mengikuti briefing?;

6. Process (Proses) dengan pertanyaan : apakah prosedur perekrutan siswa tidak diperbarui?, apakah prosedur perekrutan siswa membingungkan?, apakah prosedur terlalu manual?, apakah tidak ada komunikasi antara petugas ?

\section{HASIL DAN PEMBAHASAN}

Responden dari penelitian ini adalah siswa/i yang dikelompokkan berdasarkan kriteria, mulai dari usia, jenis kelamin, tujuan pengguna media sosial. Selanjutnya, dari hasil jawaban responden dimasukkan ke dalam tabel rekapitulasi agar bisa dilakukan pengujian. Uji kuesioner dalam penelitian ini meliputi skor rataan, uji regresi linier dan diagram tulang ikan.

Tabel 1. Hasil Perhitungan Total Responden terhadap Media Promosi

\begin{tabular}{|c|c|c|c|}
\hline Indikator & $\begin{array}{l}\text { Frekuensi } \\
\text { X bobot } \\
\text { (a) }\end{array}$ & $\begin{array}{c}\text { Skor Rataan } \\
\text { per Atribut } \\
(\mathbf{a} / 75)\end{array}$ & $\begin{array}{c}\text { Total Skor } \\
\text { Rataan } \\
\text { Dimensi } 1\end{array}$ \\
\hline MP1 & 296 & 3,95 & \multirow{6}{*}{3.63} \\
\hline MP2 & 289 & 3,85 & \\
\hline MP3 & 265 & 3,53 & \\
\hline MP4 & 281 & 3,75 & \\
\hline MP5 & 219 & 2,92 & \\
\hline MP6 & 287 & 3,83 & \\
\hline
\end{tabular}


Dari total skor rataan pendapat responden atas pertanyaan pada dimensi 1 yaitu media promosi menghasilkan skor sebesar 3,63, nilai tersebut menandakan bahwa responden memerlukan media promosi.

Tabel 2. Hasil Perhitungan Total Responden terhadap Media Sosial Sebagai Alat Informasi

\begin{tabular}{|c|c|c|c|}
\hline Indikator & $\begin{array}{c}\text { Frekuensi } \\
\text { X bobot } \\
\text { (a) }\end{array}$ & $\begin{array}{c}\text { Skor Rataan } \\
\text { per Atribut } \\
(\mathbf{a} / 75)\end{array}$ & $\begin{array}{c}\text { Total Skor } \\
\text { Rataan } \\
\text { Dimensi } 2\end{array}$ \\
\hline AF7 & 269 & 3,59 & \multirow{9}{*}{3,71} \\
\hline AF8 & 267 & 3,56 & \\
\hline AF9 & 312 & 4,16 & \\
\hline AF10 & 273 & 3,64 & \\
\hline AF11 & 265 & 3,53 & \\
\hline AF12 & 277 & 3,69 & \\
\hline AF13 & 277 & 3,69 & \\
\hline AF14 & 272 & 3,63 & \\
\hline AF 15 & 295 & 3,93 & \\
\hline
\end{tabular}

Dari total skor rataan pendapat responden atas pertanyaan pada dimensi 2 yaitu media sosial sebagai alat informasi menghasilkan skor sebesar 3,71, nilai tersebut menandakan bahwa media sosial sebagai alat informasi mempengaruhi responden.
Tabel 3. Hasil Perhitungan Total Responden terhadap Media Sosial sebagai Alat Interaktif

\begin{tabular}{|c|c|c|c|}
\hline $\begin{array}{c}\text { Indika } \\
\text { tor }\end{array}$ & $\begin{array}{c}\text { Frekuensi } \\
\text { X bobot } \\
\text { (a) }\end{array}$ & $\begin{array}{c}\text { Skor Rataan } \\
\text { per Atribut } \\
(\mathbf{a} / 75)\end{array}$ & $\begin{array}{c}\text { Total Skor } \\
\text { Rataan } \\
\text { Dimensi } 3\end{array}$ \\
\hline AA16 & 264 & 3,52 & \multirow{6}{*}{3,71} \\
\hline AA17 & 254 & 3,39 & \\
\hline AA18 & 306 & 4,08 & \\
\hline AA19 & 289 & 3,85 & \\
\hline AA20 & 264 & 3,52 & \\
\hline AA21 & 293 & 3,91 & \\
\hline
\end{tabular}

Dari total skor rataan pendapat responden atas pertanyaan pada dimensi 3 yaitu media sosial sebagai alat interaktif menghasilkan skor sebesar 3,71, nilai tersebut menandakan bahwa media sosial sebagai alat interaktif mempengaruhi responden.

Tabel 4. Hasil Perhitungan Total Responden terhadap Prospektif Penerimaan Siswa Baru

\begin{tabular}{|c|c|c|c|}
\hline Indikator & $\begin{array}{c}\text { Frekuensi } \\
\text { X bobot } \\
\text { (a) }\end{array}$ & $\begin{array}{c}\text { Skor Rataan } \\
\text { per Atribut } \\
(\mathbf{a} / 75)\end{array}$ & $\begin{array}{c}\text { Total Skor } \\
\text { Rataan } \\
\text { Dimensi 4 }\end{array}$ \\
\cline { 1 - 3 } PS22 & 294 & 3,92 & \multirow{2}{*}{3,71} \\
\cline { 1 - 2 } PS23 & 250 & 3,33 & \\
\cline { 1 - 2 } PS24 & 292 & 3,89 & \\
\hline
\end{tabular}

Sumber : Pengolahan Kuesioner

Dari total skor rataan pendapat responden atas pertanyaan pada dimensi 4 yaitu Prospektif Penerimaan Siswa Baru menghasilkan skor sebesar 3,71, nilai tersebut menandakan bahwa prospektif penerimaan siswa baru pada SMK Yadka 6 di masyarakat mempunyai prospek yang baik. 


\section{Hasil Analisis Regresi Linier}

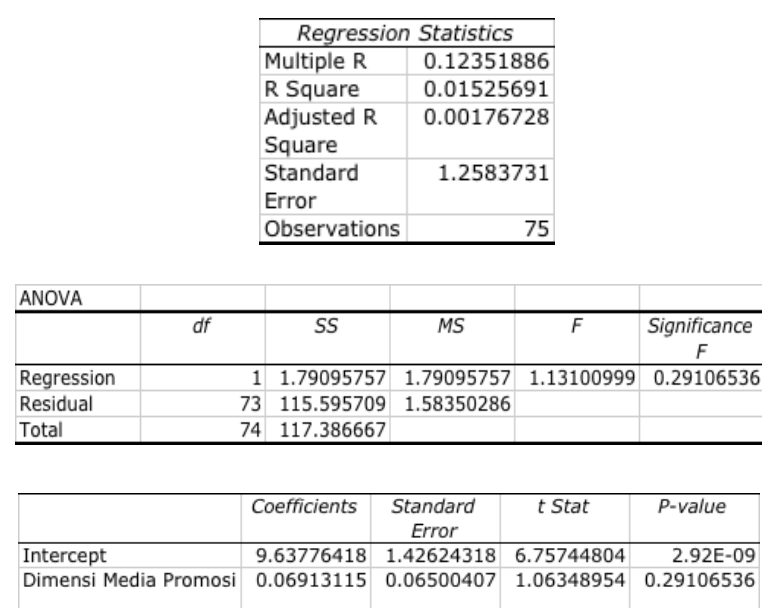

\section{Gambar 2. Uji Regresi Variabel x1 terhadap y}

Sumber: Pengolahan Kuesioner

Dari hasil di atas, nilai $\mathrm{t}$ pada media promosi sebesar 1.063 ternyata ada pengaruh persepsi terhadap prospek PSB. Setiap perkembangan yang dilakukan pada dimensi ini akan memberikan efek baik pada penerimaan siswa baru.

\begin{tabular}{|l|r|}
\hline \multicolumn{2}{|c|}{ Regression Statistics } \\
\hline Multiple R & 0.18306246 \\
\hline R Square & 0.03351187 \\
\hline $\begin{array}{l}\text { Adjusted R } \\
\text { Square }\end{array}$ & 0.0202723 \\
\hline $\begin{array}{l}\text { Standard } \\
\text { Error }\end{array}$ & 1.24665481 \\
\hline Observations & \\
\hline
\end{tabular}

\begin{tabular}{|c|c|c|c|c|c|c|}
\hline \multicolumn{7}{|l|}{ ANOVA } \\
\hline & $d f$ & & SS & $M S$ & $F$ & $\begin{array}{c}\text { Significance } \\
F\end{array}$ \\
\hline Regression & & 1 & 3.93384623 & 3.93384623 & 2.53119115 & 0.11593751 \\
\hline Residual & & 73 & 113.45282 & 1.55414823 & & \\
\hline Total & & 74 & 117.386667 & & & \\
\hline & & & efficients & $\begin{array}{c}\text { Standard } \\
\text { Error }\end{array}$ & t Stat & $P$-value \\
\hline Intercept & & & 67989516 & 1.55714911 & 5.57422221 & $3.9553 \mathrm{E}-07$ \\
\hline $\begin{array}{l}\text { Dimensi Me } \\
\text { sebagai Alat }\end{array}$ & $\begin{array}{l}\text { osial } \\
\text { rmasi }\end{array}$ & & 07379652 & 0.04638455 & 1.59097176 & 0.11593751 \\
\hline
\end{tabular}

Gambar 3. Uji Regresi Variabel x2 terhadap y

Sumber : Pengolahan Kuesioner

Hasil R Square diatas adalah 0.033, hal ini menandakan bahwa hanya 3\% saja dari total variasi dimensi 2 yang dapat dijelaskan oleh variasi dari variabel Prospek PSB. Sedang 97\%nya dapat dijelaskan diluar dimensi Media Sosial sebagai Alat Informasi. Terdapat pengaruh antar dimensi yang ditunjukkan oleh nilai t sebesar 1.5909.

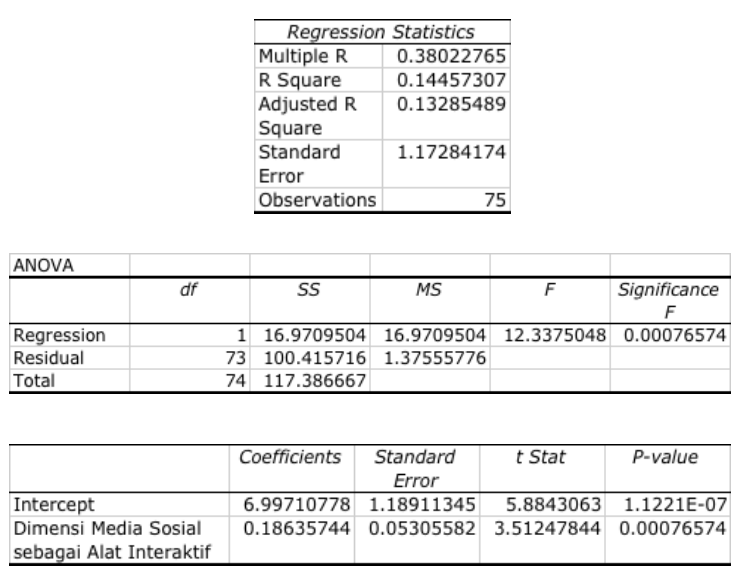

\section{Gambar 4. Uji Regresi Variabel x3 terhadap y}

Sumber : Pengolahan Kuesioner

Dari hasil di atas, nilai $\mathrm{R}$ Square adalah 0.144 . Hal ini menandakan bahwa $14 \%$ dari total variasi Media Sosial sebagai Alat Interaktif dapat dijelaskan oleh variasi variabel Prospek PSB. 86\% nya dijelaskan di luar dari variasi Prospek PSB. Ada persepsi pengaruh yang besar yang ditunjukkan oleh nilai t sebesar 3.512.

\begin{tabular}{|c|c|c|c|c|c|c|}
\hline & & Regr & ession St & atisti & & \\
\hline & & Multiple R & & & 8478888 & \\
\hline & & R Square & & & 4806249 & \\
\hline & & Adjusted $\mathrm{R}$ & Square & & 1206513 & \\
\hline & & Standard $\mathrm{E}$ & rror & & 8681788 & \\
\hline & & Observation & & & 75 & \\
\hline ANOVA & & & & & & \\
\hline & $d f$ & $S S$ & $M S$ & & $\bar{F}$ & Significance $F$ \\
\hline Regression & 3 & 17.3805616 & 5.79352 & 2053 & 4.11314847 & 0.00950017 \\
\hline Residual & 71 & 100.006105 & 1.40853 & 3669 & & \\
\hline Total & 74 & 117.386667 & & & & \\
\hline & & $\begin{array}{c}\text { Coeffici } \\
\text { ents }\end{array}$ & $\begin{array}{c}\text { Standarc } \\
\text { Error }\end{array}$ & & t Stat & $P$-value \\
\hline Intercept & & 6.6635 & 1.88160 & 418 & 3.54140157 & 0.00070759 \\
\hline Dimensi Me & Promosi & 0.0315 & $0.06265 \mathrm{~s}$ & & 0.50249736 & 0.61687276 \\
\hline $\begin{array}{l}\text { Dimensi Mec } \\
\text { sebagai Alat }\end{array}$ & $\begin{array}{l}\text { Sosial } \\
\text { formasi }\end{array}$ & -0.012 & 0.05224 & 492 & -0.23873638 & 0.81199775 \\
\hline $\begin{array}{l}\text { Dimensi Mec } \\
\text { sebagai Alat }\end{array}$ & $\begin{array}{l}\text { Sosial } \\
\text { teraktif }\end{array}$ & 0.1892 & 0.063708 & 857 & 2.96976089 & 0.00406296 \\
\hline
\end{tabular}

Gambar 5. Uji Regresi x1, x2 dan x3 terhadap y

Sumber : Pengolahan Kuesioner 
Dari hasil penelitian di atas, maka dimensi Media Sosial sebagai Alat Interaktif mempunyai pengaruh yang besar dibanding dimensi lain dengan nilai $t$ sebesar 2.969. Koefisien determinan yang ditunjukkan oleh nilai Adjusted R Square sebesar 0.112 , maka hanya $11 \%$ dari model ini yang dapat menjelaskan variabel dependen (Prospek PSB) dari variasi ketiga variabel independen (Media Promosi, Media Sosial sebagai Alat Informasi dan Media Sosial sebagai Alat Interaktif). 89\% nya dapat dijelaskan oleh sebab-sebab di luar dari model ini.

\section{Hasil Hipotesis}

\section{Hipotesis 1}

Berdasarkan analisis data di atas, nilai signifikansi pada variabel Media Promosi (X1) sebesar $0.291>0.05$ dan t hitung sebesar 1.063 < dari $\mathrm{t}$ tabel 1.66543 . Sehingga diinterpretasikan bahwa variabel Media Promosi tidak mempunyai pengaruh yang signifikan terhadap variabel dependen Prospek PSB, dengan demikian hipotesis $\mathrm{H} 0$ diterima.

\section{Hipotesis 2}

Berdasarkan analisis data di atas, nilai signifikansi pada variabel Media Sosial sebagai Alat Informasi (X2) sebesar 0.115 $>0.05$ dan $\mathrm{t}$ hitung sebesar $1.590<$ dari $\mathrm{t}$ tabel 1.66543. Sehingga diinterpretasikan bahwa variabel Media Sosial sebagai Alat Informasi tidak mempunyai pengaruh yang signifikan terhadap variabel dependen Prospek PSB, dengan demikian hipotesis 1 dan 2 pada kerangka pemikiran ditolak.

\section{Hipotesis 3}

Berdasarkan analisis data di atas, nilai signifikansi pada variabel Media Sosial sebagai Alat Interaktif (X3) sebesar 0.000 $<0.05$ dan $\mathrm{t}$ hitung sebesar $3.512>$ dari $\mathrm{t}$ tabel 1.66543. sehingga diinterpretasikan bahwa variabel Media Sosial sebagai Alat Interaktif mempunyai pengaruh yang signifikan terhadap variabel dependen Prospek PSB, dengan demikian hanya hipotesis 3 pada kerangka pemikiran yang H1nya diterima.

Tabel 5. Sebab Utama Keberhasilan Promosi pada Penerimaan Siswa Baru pada SMK Yadika 6, Bekasi

\begin{tabular}{|c|c|c|}
\hline $\begin{array}{c}\text { KEMUNGKIN } \\
\text { AN } \\
\text { PENYEBAB } \\
\text { UTAMA }\end{array}$ & DISKUSI & $\begin{array}{c}\text { SEBAB } \\
\text { UTAM } \\
\text { A ? }\end{array}$ \\
\hline \multicolumn{3}{|c|}{ PRODUCT (Produk / Jasa) } \\
\hline $\begin{array}{l}\text { Jasa promosi } \\
\text { kurang tepat }\end{array}$ & $\begin{array}{l}\text { Pengambilan keputusan } \\
\text { tentang jasa iklan / } \\
\text { promosi tepat }\end{array}$ & Tidak \\
\hline $\begin{array}{l}\text { Jasa promosi } \\
\text { tidak diterima }\end{array}$ & $\begin{array}{l}\text { Belum semua calon } \\
\text { siswa mengakses } \\
\text { informasi promosi } \\
\text { melalui internet }\end{array}$ & Ya \\
\hline \multicolumn{3}{|l|}{ PRICE (Harga) } \\
\hline $\begin{array}{l}\text { Biaya promosi } \\
\text { tidak sesuai }\end{array}$ & $\begin{array}{l}\text { Biaya promosi sesuai } \\
\text { dengan anggaran belanja }\end{array}$ & Tidak \\
\hline $\begin{array}{l}\text { Anggaran } \\
\text { pendukung tidak } \\
\text { disiapkan }\end{array}$ & $\begin{array}{l}\text { Biaya lain-lain } \\
\text { dikeluarkan secara } \\
\text { kolektif bersama } \\
\text { kegiatannya }\end{array}$ & Tidak \\
\hline \multicolumn{3}{|l|}{ PLACE (Tempat) } \\
\hline $\begin{array}{l}\text { Penempatan } \\
\text { iklan tidak } \\
\text { sesuai }\end{array}$ & $\begin{array}{l}\text { Penempatan iklan } \\
\text { spanduk dan pada media } \\
\text { sosial sesuai prosedur }\end{array}$ & Tidak \\
\hline $\begin{array}{l}\text { Pemilihan media } \\
\text { sosial tidak tepat }\end{array}$ & $\begin{array}{l}\text { Media sosial dipilih } \\
\text { berdasarkan survey } \\
\text { global }\end{array}$ & Tidak \\
\hline
\end{tabular}




\begin{tabular}{|c|c|c|}
\hline $\begin{array}{c}\text { KEMUNGKIN } \\
\text { AN } \\
\text { PENYEBAB } \\
\text { UTAMA }\end{array}$ & DISKUSI & $\begin{array}{c}\text { SEBAB } \\
\text { UTAM } \\
\text { A ? }\end{array}$ \\
\hline \multicolumn{3}{|c|}{ PROMOTION (Promosi) } \\
\hline $\begin{array}{l}\text { Kerja sama } \\
\text { dengan pihak } \\
\text { penyedia iklan / } \\
\text { jasa internet }\end{array}$ & $\begin{array}{l}\text { Intensif dan sesuai aturan } \\
\text { yang telah berlaku }\end{array}$ & Tidak \\
\hline $\begin{array}{l}\text { Tidak ada } \\
\text { sosialisasi jasa } \\
\text { baik lewat } \\
\text { manual maupun } \\
\text { internet }\end{array}$ & $\begin{array}{l}\text { Sosialisasi promosi } \\
\text { manual dan internet } \\
\text { sudah dilakukan }\end{array}$ & Tidak \\
\hline \multicolumn{3}{|c|}{ PEOPLE (Manusia) } \\
\hline $\begin{array}{l}\text { Kemampuan } \\
\text { karyawan } \\
\text { dalam } \\
\text { melakukan tugas }\end{array}$ & $\begin{array}{l}\text { Pelaksanaan tugas sesuai } \\
\text { dengan perintah } \\
\text { pengambil keputusan. }\end{array}$ & Tidak \\
\hline $\begin{array}{l}\text { Tidak tahu } \\
\text { prosedur } \\
\text { pemasangan } \\
\text { iklan / promosi } \\
\text { via internet }\end{array}$ & $\begin{array}{l}\text { Briefing pemasangan } \\
\text { iklan / promosi sudah } \\
\text { disediakan }\end{array}$ & Tidak \\
\hline $\begin{array}{l}\text { Tidak mengikuti } \\
\text { prosedur } \\
\text { pemasangan } \\
\text { iklan / promosi } \\
\text { via internet }\end{array}$ & $\begin{array}{l}\text { Karyawan mengikuti } \\
\text { instruksi hingga } \\
\text { pembayaran iklan dan } \\
\text { kiat-kiat promosi }\end{array}$ & Tidak \\
\hline $\begin{array}{l}\text { Tidak mengikuti } \\
\text { briefing }\end{array}$ & $\begin{array}{l}\text { Karyawan wajib hadir } \\
\text { dalam briefing PSB dan } \\
\text { sistem penalti }\end{array}$ & Tidak \\
\hline \multicolumn{3}{|c|}{ PROCESS (Proses) } \\
\hline $\begin{array}{l}\text { Prosedur } \\
\text { perekrutan tidak } \\
\text { diperbarui }\end{array}$ & $\begin{array}{l}\text { Evaluasi prosedur } \\
\text { perekrutan rutin setahun } \\
\text { sekali }\end{array}$ & Tidak \\
\hline $\begin{array}{l}\text { Prosedur } \\
\text { perekrutan } \\
\text { membingungkan }\end{array}$ & $\begin{array}{l}\text { Prosedur sudah ditinjau } \\
\text { oleh petugas PSB, wakil } \\
\text { serta kepsek. }\end{array}$ & Tidak \\
\hline
\end{tabular}

\begin{tabular}{|l|l|c|}
\hline $\begin{array}{c}\text { KEMUNGKIN } \\
\text { AN } \\
\text { PENYEBAB } \\
\text { UTAMA }\end{array}$ & \multicolumn{1}{|c|}{ DISKUSI } & $\begin{array}{c}\text { SEBAB } \\
\text { UTAM } \\
\text { A ? }\end{array}$ \\
\hline Lanjutan PROCESS (Proses) & Ya \\
\hline $\begin{array}{l}\text { Prosedur terlalu } \\
\text { manual }\end{array}$ & $\begin{array}{l}\text { Petugas PSB ialah guru, } \\
\text { selain mengajar harus } \\
\text { presentasi ke sekolah- } \\
\text { sekolah, mengantar surat } \\
\text { undangan, menunggu } \\
\text { meja piket PSB, } \\
\text { menjelaskan detail } \\
\text { informasi kepada calon } \\
\text { siswa, dll }\end{array}$ & Tidak \\
\hline $\begin{array}{l}\text { Tidak ada } \\
\text { komunikasi } \\
\text { antara petugas }\end{array}$ & $\begin{array}{l}\text { Komunikasi terjalin real } \\
\text { time, terkini sesuai } \\
\text { kondisi lapangan }\end{array}$ & Sumber : Pengolahan Kuesioner \\
\hline
\end{tabular}

\section{SIMPULAN}

1. Media sosial tidak selalu mempunyai pengaruh yang besar sebagai alat promosi khususnya pada SMK Yadika 6 , ternyata hanya satu dari tiga dimensi penelitian yang dapat dibuktikan mempunyai dampak bagi penerimaan calon siswa baru.

2. Jasa promosi tidak diterima oleh masyarakat karena belum meratanya akses informasi melalui internet bagi calon siswa baru, ini juga satu masalah bagi efektivitas penggunaan media sosial.

3. Media sosial yang digunakan tidak diimbangi oleh prosedur perekrutan calon siswa yang disimpulkan masih bersifat manual, sehingga petugas PSB (guru) mengalami kendala dalam membagi waktu antara mengajar dan presentasi ke sekolah-sekolah, mengantar surat undangan, menunggu meja piket PSB, menjelaskan detail informasi kepada calon siswa, dll. 


\section{DAFTAR PUSTAKA}

1. Lee, N., Facebook Nation. Springer Science+Business Media. New York. Chapter 8, 2014.

2. Van Looy, A., Social Media Management. Springer Texts in Business and Economics. Springer International Publishing Switzerland. pp 21-47, 2016.

3. Hanley, Loo, Chee Aik, T.O., Keat Kheng, R.W. \& Yew, L.S., A Study on the Academic Uses of Facebook in Vocational Education. IEEE, 2013.

4. Jimbo, Yosuke, Masaki Kohana and Shusuke Okamoto. A Twitter Service for School Event. Second International Conference on Networking and Computing. IEEE. pp 266-270, 2011.

5. Chelly, Magda, Mataillet, H., Social Media and the Impact on Education. Social Media and Home Education. IEEE. pp 236-239, 2012.

6. Almadhoun, N.M., Dominic, P.,D., D., and Lai Fong Woon. Social Media as a Promotional Tool in Higher Education in Malaysia. IEEE, 2011.

7. Bardin, L. Analise de Conteudo. Lisboa-Portugal. Edition 70, 2010.

8. Sugiyono. Metode Penelitian Kuantitatif, Kualitatif dan RD. Alfabeta-Bandung, 2010.

9. Kolb, B. Marketing research a practical approach. Sage Publications. California. Pp110-192, 2008.

10. Da Silva, A.L., Barbosa, M. P., Facebook Groups: the use of social network in the education. IEEE. pp 185-188, 2015.

11. Guo, W. and $\mathrm{Lu}, \mathrm{H}$, Using Fishbone Diagrams in Inquiry-Based Teaching and Learning for Engineering Education. Springer-Verlag Berlin Heidelberg. Pg. 435-442, 2011.

12. Paris, C.M., Lee, W., Seery, P., The Role of Social Media in Promoting Special Events: Acceptance of Facebook "Events". pp 531-541, 2010.
13. Turban, E., et al., Social Commerce: Marketing, Technology and Management. Springer Texts in Business and Economics. Springer International Publishing Switzerland. Chapter 4, 2016.

14. Safko-Brake, The Social Media Bible, Tactics, Tools and Strategies for Business Success. John Willey \& Sons. New Jersey, 2009.

15. Kaplan, A.M., Haenlein, M., Users of The World Unite! The challenges and opportunities of Social Media. Elsevier. Pp 59-68, 2010.

16. Berry, M., Mobile Media Making in an age of Smartphones. Slow Media Creation and the Rise of Instagram. Palgrave Macmillan. Pp 129-138, 2014.

17. Ehlers, U.D., Open Learning Cultures. Springer-Verlag Berlin Heidelberg. Chapter 2, 2013.

18. Fischer, Eileen and Reuber, A.R., Social interaction via new social media: (How) can interactions on Twitter affect effectual thinking and behavior?. Elsevier, 2011.

19. Sanchez, J.L., Gonzalez, C.S., Alayon, S. and Gonzalez P., Using Social Networks at University: the case of School of Computer Science. EDUCON. IEEE. pp 492-496, 2013.

20. Kurniawati, Elisabeth., Analisis Efektifitas Media Promosi Sekolah YSKI di Semarang dalam penerimaan Siswa Baru. Unika Soegijapranata, 2013.

21. Oster, E. and Steinberg, B.M., Do IT service center promote school enrollment? Evidence from India., Elsevier. 2013. 